\title{
НЕЛІНІЙНІ ПРОЦЕСИ
}

\begin{abstract}
(Просп. Комарова, 1, Київ 03058)
У межах квазікласичного підходу вивчено солітонні стани, які локалізовані біля плоского дефектного шару, що має нелінійні властивості, при різних знаках нелінійності середовища та різному характері взаємодії елементарних збуджень системи 3 дефектним шаром. Надано квантову інтерпретацію цих нелінійних локалізованих мод на мові зв'язаних станів великої кількості елементарних збуджень. Визначено області існування та досліджено властивості таких станів залежно від характеру взаємодії елементарних збуджень між собою та з дефектом.
\end{abstract}

ЛОКАЛІЗОВАНІ СТАНИ У НЕЛІНІЙНОМУ СЕРЕДОВИЩІ $З$ ПЛОСКИМ ДЕФЕКТНИМ ШАРОМ, ЯКИЙ МАЕ НЕЛІНІЙНІ ВЛАСТИВОСТІ

\author{
І.В. ГЕРАСИМЧУК, ${ }^{1}$ П.К. ГОРБАЧ, ${ }^{2}$ П.П. ДОВГОПОЛИЙ ${ }^{2}$ \\ ${ }^{1}$ Інститут магнетизму НАН України та МОНМС України \\ (Булъв. Академіка Вернадсъкого, 36-б, Kиїв 03142; e-mail: igor. gera@gmail. com)
}

${ }^{2}$ Національний авіаційний університет

\section{1. Вступ}

Проведене у даній роботі дослідження має безпосереднє відношення до досить нового і актуального напрямку сучасної теоретичної фізики - теорії нелінійних хвиль і солітонів у фізиці твердого тіла. Останні дослідження в цій області спрямовані на вивчення солітонів в реальних фізичних системах з урахуванням їх дискретності, дефектності, внутрішньої мікроструктури та інших особливостей. 3 точки зору технологічних застосувань найбільший інтерес викликають багатошарові структури різного типу. Наприклад, магнітні багатошарові системи, використання яких викликає інтерес через магнітооптичні властивості такого багатошарового матеріалу, а також явища гігантського магнітоопору в них. Сюди також можна віднести багатошарові кристали з багатоатомним елементарним осередком, ВТНП-сполуки та ін. У нелінійній оптиці шаруваті та модульовані середовища використовуються у волоконних системах, оптичних лініях затримки і т. д. (див., наприклад, $[1,2])$.

У нелінійній оптиці, зазвичай, розглядається нелінійне середовище (наприклад, магнетик, пружний кристал або оптично прозорий діелектрик), що містить вузькі шари, які відрізняються від самого середовища своїми властивостями. Для хвиль стаціонарного профілю проблема еквівалентна дослідженню нелінійних збуджень в одновимірній системі 3 точковими дефектами (нелінійних локальних коливань). Для одного ізольованого дефекту таку задачу було детально досліджено у роботах $[3,4]$ для різних знаків нелінійності середовища і різного характеру взаємодії елементарних збуджень з дефектом. При цьому проводилося вивчення системи 3 дефектом, який мав лінійні властивості. Системи 3 нелінійними дефектами в лінійному оточуючому середовищі вивчали, наприклад, у роботах $[5,6]$.

У даній роботі у межах нелінійного рівняння Шредінгера $з$ довільним знаком нелінійності середовища досліджено збудження, які локалізовані поблизу плоского, але нелінійного дефектного шару, як у випадку взаємного притягання між елементарними збудженнями i дефектним шаром, так i при ix взаємному відштовхуванні. Для кращого розуміння фізичної природи розглянутих нелінійних локалізованих станів проведено квазікласичне квантування і отримано зв'язок повної енергії системи 3 числом зв'язаних в ній елементарних збуджень. 


\section{2. Солітонні стани, які локалізовані поблизу дефектного шару}

Під час дослідження солітонних збуджень, ефективний розмір яких залежно від частоти солітону може змінюватися у широких межах, локальним дефектом будемо вважати збурення характеристик нелінійного середовища, яке зосереджено на відстанях, набагато менших від ширини солітону. За наявності такого дефекту з нелінійними властивостями нелінійне рівняння Шредінгера (НРШ) для польової змінної $u(z, t)$ має вигляд

$i \frac{\partial u}{\partial t}+\frac{\partial^{2} u}{\partial z^{2}}+2 \sigma|u|^{2} u=-\lambda \delta(z)|u|^{2} u$

де $\sigma= \pm 1$ характеризує взаємодію елементарних збуджень $(\sigma=+1$ відповідає їх взаємному притяганню, $\sigma=-1$ - відштовхуванню), і $\lambda$ - характеристика величини дефекту (його "потужність"). При $\lambda>0$ елементарні збудження ефективно притягуються до дефекту, а при $\lambda<0$ - відштовхуються від нього.

$\mathrm{У}$ середовищі без дефектів $(\lambda=0)$ у лінійній межі $(\sigma=0)$ закон дисперсії лінійних хвиль $u(z, t) \sim$ $\exp \{i(k z-\omega t)\}$ має вигляд $\omega=k^{2}$, а спектр лінійних збурень займає піввісь $\omega \geq 0$.

Відзначимо, що у лінійному середовищі за наявності дефекту також існують локалізовані на дефекті коливання. Для лінійного дефекта з "потужністю" $\lambda$ (коли права частина рівняння (1) дорівнює $-\lambda \delta(z) u$ ) такі локалізовані стани можливі тільки у випадку притягуючого дефекту $(\lambda>0)$ [4]. Їх частота дорівнює $\omega=-\lambda^{2} / 4$ і лежить під нижньою межею суцільного спектра. При $\lambda<0$ такі локалізовані коливання відсутні.

Для нелінійного дефекту, що розглядається у даній роботі, у випадку лінійного середовища рівняння, що відповідає рівнянню (1), буде мати такий розв'язок для стаціонарного локалізованого стану:

$u=u_{0} \exp \{-\varepsilon|z|-i \omega t\}$

де $\varepsilon=\sqrt{-\omega}$ i $u_{0}=\sqrt{\frac{2}{\lambda}} \sqrt{\varepsilon}$.

Таким чином, ми маємо таку саму залежність частоти локалізованого стану $\omega$ від амплітуди поля у місці розташування дефекту, що і для частоти ангармонічного осцилятора від амплітуди його коливань:

$\omega=-\frac{\lambda^{2}}{4} u_{0}^{4}$
Якщо ввести повне число елементарних збуджень у системі

$$
N=\int_{-\infty}^{+\infty}|u|^{2} d z
$$

та повну енергію системи

$W=\int_{-\infty}^{+\infty}\left\{\left|\frac{\partial u}{\partial z}\right|^{2}-\frac{\lambda}{2} \delta(z)|u|^{4}\right\} d z$

то виявляється, що для такої моделі зазначені характеристики системи не залежать від частоти:

$N=\frac{2}{\lambda}, \quad W=0$.

Однак така властивість не є універсальною. При врахуванні нелінійності середовища поблизу дефекту, коли в лівій частині (1) присутній доданок $2 \sigma|u|^{2} u$, та при врахуванні тільки лінійних властивостей дефекту отримуємо залежності [4]:

$N=2 \sigma\left(\varepsilon-\frac{\lambda}{2}\right), \quad W=-\frac{\sigma}{3}\left(2 \varepsilon^{3}-\frac{\lambda^{3}}{4}\right)$.

Рівняння руху (1) є ейлеровим рівнянням для лагранжіана з такою густиною:

$L=\frac{i}{2}\left(u^{*} \frac{\partial u}{\partial t}-u \frac{\partial u^{*}}{\partial t}\right)-\left|\frac{\partial u}{\partial z}\right|^{2}+\sigma|u|^{4}+\frac{\lambda}{2} \delta(z)|u|^{4}$.

Будемо шукати стаціонарні розв'язки НРШ (1) у вигляді

$u(z, t)=u(z) \exp (-i \omega t)$,

де $u(z) \rightarrow 0$ при $z \rightarrow \pm \infty$. Тоді рівняння (1) для функції $u(z)$ отримає такий вигляд:

$\frac{\partial^{2} u}{\partial z^{2}}+\omega u+2 \sigma u^{3}=-\lambda \delta(z) u^{3}$

Розв'язок рівняння (10) зводиться до розв'язання однорідного рівняння

$\frac{\partial^{2} u}{\partial z^{2}}+\omega u+2 \sigma u^{3}=0$

в областях $z>0$ та $z<0$ з граничними умовами в точці $z=0$ :

$\left.u\right|_{+0}=\left.u\right|_{-0}$, 

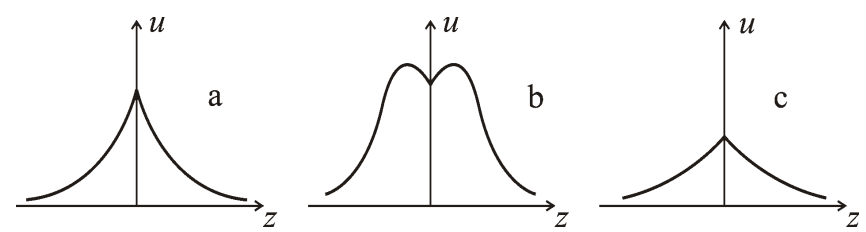

Рис. 1. Розподіл поля у нелінійному локалізованому стані у випадках: a) $\sigma=+1, \lambda>0$; b) $\sigma=+1, \lambda<0$; c) $\sigma=-1, \lambda>0$

$$
\left.\frac{\partial u}{\partial z}\right|_{+0}-\left.\frac{\partial u}{\partial z}\right|_{-0}=-\left.\lambda u^{3}\right|_{0} \cdot
$$

У випадку $\sigma=+1$ розв'язок, який задовольняе граничні умови, має вигляд

$u(z)=\frac{\varepsilon}{\operatorname{ch}\left[\varepsilon\left(|z|-z_{0}\right)\right]}$,

де параметр $\varepsilon \equiv \sqrt{-\omega}$ характеризує амплітуду розв'язку, область його локалізації та частоту збудження, а параметри $\varepsilon$ і $z_{0}$ зв'язані співвідношенням, яке випливає з другої граничної умови (13):

$\operatorname{sh}\left(2 \varepsilon z_{0}\right)=-\lambda \varepsilon$.

Зі співвідношення (15) видно, що $\operatorname{sgn} z_{0}=-\operatorname{sgn} \lambda$; при будь-якому знаку $\lambda$ інтервал припустимих частот необмежений знизу, а максимально можлива частота розв'язку дорівнює нулю і збігається з нижньою межею спектра лінійних хвиль.

У випадку $\sigma=-1$ розв'язок, який задовольняє граничні умови, буде мати вигляд

$u(z)=\frac{\varepsilon}{\operatorname{sh}\left[\varepsilon\left(|z|-z_{0}\right)\right]}$.

Величина $z_{0}$ може мати тепер тільки від'ємні значення, оскільки локалізований стан $\sigma=-1$ реалізується тільки у випадку притягуючого характеру дефекту $(\lambda>0)$. Зв'язок між параметрами $\varepsilon$ i $z_{0}$ визначає тим самим співвідношенням (15), що і для випадку $\sigma=+1$. Зі співвідношення (15) випливає, що при додатних $\lambda$ має бути $z_{0}<0$.

Як і в попередньому випадку $(\sigma=+1)$, інтервал допустимих частот необмежений знизу, а максимальному (нульовому) значенню відповідає межа спектра лінійних хвиль.

Таким чином, нелінійні локалізовані стани існують при таких співвідношеннях параметрів $\sigma$ і $\lambda: a-\sigma=$ $+1, \lambda>0 ; b-\sigma=+1, \lambda<0$; i $c-\sigma=-1, \lambda>0$. Такі ж локалізовані стани існували і у системі в роботі [4]. Розглянемо структуру рішень в цих трьох випадках (рис. 1) детальніше.

а) При $\sigma=+1, \lambda>0$ максимум амплітуди коливання знаходиться у точці розташування домішки (оскільки $z_{0}<0$ ), і розв'язок має вигляд, зображений на рис. 1, a. У даному випадку елементарні збудження притягуються як між собою, так і до дефекту.

Поблизу межі спектра лінійних хвиль, коли $\omega \rightarrow 0$ $(\varepsilon \rightarrow 0)$, із співвідношення $(15)$ випливає, що $z_{0} \approx$ $-\lambda / 2$, а амплітуда локалізованого стану залежить від частоти так:

$$
\left.u(z=0)\right|_{\omega \rightarrow 0} \approx \sqrt{-\omega} .
$$

При $\omega=0$ нелінійна локалізована мода перетворюється на звичайні коливання лінійної теоріі.

b) При $\sigma=+1, \lambda<0$ елементарні збудження притягуються між собою, але відштовхуються від дефекту, і максимум амплітуди коливання не збігається 3 місцем розташування дефекту. Локалізований стан це зв'язаний стан двох солітонів, які симетрично розташовані по обидва боки дефекту з центрами в точках $\pm z_{0}$ (рис. $\left.1, b\right)$.

У межі максимально можливої частоти розв'язку $(\omega \rightarrow 0)$ відстань між зв'язаними солітонами прагне до сталої величини: $2 z_{0} \approx-\lambda=|\lambda|$, а амплітуда коливань дефекту прямує до нуля відповідно до (17). Амплітуда солітонів також прямує до нуля:

$\left.A\right|_{\omega=0}=\left.u\left(z= \pm z_{0}\right)\right|_{\omega=0}=\left.\varepsilon\right|_{\omega=0}=0$

і ця межа є малоамплітудною.

c) У випадку $\sigma=-1, \lambda>0$ (збудження відштовхуються одне від одного, але притягуються до дефекту) профіль локалізованого збудження має приблизно такий самий вигляд, що і при $\sigma=+1, \lambda>0$ (випадок $a$ ) - максимум амплітуди коливання знаходиться в точці розташування дефекту (рис. 1,c), i такий самий частотний інтервал існування локальної моди: $-\infty<\omega<0$.

$\mathrm{У}$ лінійній межі $(\omega \rightarrow 0)$, як і у випадку $a$, параметр $z_{0} \approx-\lambda / 2$, але амплітуда коливання домішки прямує тепер до кінцевої величини (порів. $з$ (17)):

$\left.u(z=0)\right|_{\omega \rightarrow 0} \approx \frac{2}{\lambda}$,

а сам розв'язок для локалізованого стану (16) трансформується у функцію зі степеневими асимптотиками на нескінченності, тобто в алгебраїчний солітон вигляду

$u(z)=\frac{1}{|z|+\lambda / 2}$.

Раніше (у роботі [4]) було зазначено, що, зазвичай, можливість існування степеневих солітонів на межі 
суцільного спектра лінійних хвиль пов'язана з урахуванням конкуруючих нелінійностей в еволюційних рівняннях або за наявності багато-частинкових взаємодій різного типу [7]. Наприклад, до виникнення алгебраїчних солітонів на межі спектра лінійних хвиль приводить урахування парного відштовхування квазічастинок та їх тричастинкового притягання, тобто врахування доданків типу $u|u|^{4}$ у рівнянні (1) 3 $\sigma=-1$. Раніше було показано, що такі солітони $€$ нестійкими [8].

У випадку з дефектом, що розглядається нами, ситуація багато в чому схожа: є два типи взаємодій парна міжчастинкова взаємодія, що описується доданком $2 \sigma|u|^{2} u$, та одночастинкова взаємодія елементарних збуджень з неоднорідністю, ефективна інтенсивність якої, однак, залежить від величини поля: $\lambda_{\text {eff }}=\lambda|u|^{2}$ (у роботі [4] інтенсивність одночастинкової взаємодії визначалася константою $\lambda$ ). Степеневі солітони у нашому випадку існують при парному відштовхуванні квазічастинок $(\sigma=-1)$ та їх притягуванні до дефекту $(\lambda>0)$.

Як видно з розгляду 3-х можливих локалізованих станів, на відміну від системи [4] всі локалізовані стани нашої системи існують в одному частотному інтервалі: $-\infty<\omega<0$.

Для кращого розуміння фізичної природи розглянутих локалізованих станів проведемо їх квазікласичне квантування.

Рівняння (1) описує динаміку консервативної системи і тому має очевидний інтеграл руху - повну енергію системи:

$W=\int_{-\infty}^{+\infty} d z\left\{\left|\frac{\partial u}{\partial z}\right|^{2}-\sigma|u|^{4}-\frac{\lambda}{2} \delta(z)|u|^{4}\right\}$

а також воно має додатковий інтеграл руху (4) - повне число елементарних збуджень (квантів поля), локалізованих у системі [3].

До цього часу ми характеризували локалізований розв'язок його частотою $\omega$ (параметром $\varepsilon$ ). Для розуміння квантово-механічної природи солітонного стану зручно перейти від частоти як його динамічної характеристики до числа зв'язаних у цьому локалізованому стані збуджень $N$.

Розглянемо спочатку випадок $\sigma=+1$. Виразимо інтеграли руху $N$ і $W$ через частоту $\omega$ (або зв'язаний із нею параметр $\varepsilon$ ). Підставляючи явний вигляд розв'язку (14) у вираз (4) та враховуючи при цьому залежність $z_{0}(\varepsilon)$ (див. (15)), отримуємо співвідноше- ння, яке визначає повне число збуджень $N$ :

$$
N=2 \varepsilon\left(1+\operatorname{th}\left(\varepsilon z_{0}\right)\right)=2 \varepsilon+\frac{2}{\lambda}\left(1-\sqrt{1+(\lambda \varepsilon)^{2}}\right) .
$$

3 отриманого співвідношення легко визначити, що при позитивних значеннях $\lambda$ (притягуючому характеpi дефекту) повне число збуджень у системі має обмеження зверху:

$0 \leq N<2 / \lambda, \quad \lambda>0$

При цьому $N \rightarrow 2 / \lambda$ при $\varepsilon \rightarrow+\infty ; N \rightarrow 0$ при $\varepsilon \rightarrow 0$.

Відзначимо, що критичне значення $N^{*}=2 / \lambda$ відповідає повному числу збуджень у системі з нелінійним дефектом у лінійному середовищі (див. (6)).

При $\lambda<0$ величина $N$ може набувати будь-яких додатних значень:

$N \geq 0, \quad \lambda<0$.

Зі співвідношення (22) легко отримати обернену залежність $\varepsilon=\varepsilon(N)$ :

$\varepsilon=\frac{N}{4} \frac{4-\lambda N}{2-\lambda N}$

i, відповідно, залежність $\omega=\omega(N)$ :

$\omega=-\left(\frac{N}{4}\right)^{2}\left(\frac{4-\lambda N}{2-\lambda N}\right)^{2}=-\left(\frac{N}{4}\right)^{2}\left(1+\frac{2}{2-\lambda N}\right)^{2}$.

Аналогічно, використовуючи явний вигляд розв'язку (14) у виразі (21) та враховуючи співвідношення (15), можна отримати в явному вигляді залежність повної енергії системи $W$ від параметра $\varepsilon: W=W(\varepsilon)$. Далі, виключаючи з виразу для $W=W(\varepsilon)$ та залежності $N=N(\varepsilon)(22)$ параметр $\varepsilon$ за допомогою формули (25), легко отримати зв'язок повної енергії локалізованого стану з повним числом зв'язаних у ньому елементарних збуджень:

$W(N)=\frac{N^{3}}{6}-\frac{\lambda N^{4}}{32}-\frac{N^{3}}{32} \frac{(4-\lambda N)^{2}}{2-\lambda N}$.

Ще раз відзначимо, що повне число збуджень $N$ не може перевищувати максимального значення $N^{*}=$ $2 / \lambda(23)$.

Звернемось тепер до випадку $\sigma=-1$. Підставляючи розв'язок (16) у формулу (4) для $N$ та використовуючи залежність $z_{0}(\varepsilon)$ зі співвідношення (15), отримуємо залежність $N=N(\varepsilon)$ (відмінну від виразу (22) для випадку $\sigma=+1)$ :

$N=-2 \varepsilon\left(1+\operatorname{cth}\left(\varepsilon z_{0}\right)\right)=-2 \varepsilon+\frac{2}{\lambda}\left(1+\sqrt{1+(\lambda \varepsilon)^{2}}\right)$. 


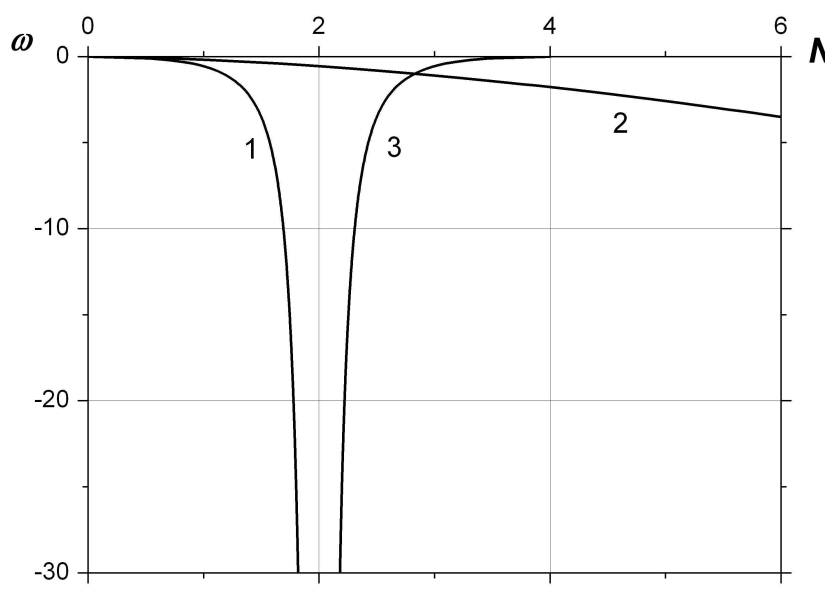

Рис. 2. Залежності $\omega=\omega(N)$ для трьох можливих типів нелінійних локалізованих станів: $a) \sigma=+1, \lambda=+1$ (крива 1$) ; b$ ) $\sigma=+1, \lambda=-1$ (крива 2); c) $\sigma=-1, \lambda=+1$ (крива 3)

3 отриманого співвідношення легко визначити, що повне число збуджень у системі $N$ лежить у діапазоні (параметр $\lambda$ додатний у випадку $\sigma=-1$ ):

$2 / \lambda<N \leq 4 / \lambda$

При цьому $N \rightarrow 2 / \lambda$ при $\varepsilon \rightarrow+\infty$, та $N \rightarrow 4 / \lambda$ при $\varepsilon \rightarrow 0$.

3 виразу (28) легко визначити обернену залежність $\varepsilon=\varepsilon(N)$ (порів. $3(25))$ :

$\varepsilon=-\frac{N}{4} \frac{4-\lambda N}{2-\lambda N}$

При цьому залежність $\omega=\omega(N)$ у випадку $\sigma=-1$ має такий самий аналітичний вигляд (26), що і для випадку $\sigma=+1$.

Такою самою, як і для випадку $\sigma=+1$, виявляється і залежність (27) повної енергії локалізованого стану від кількості зв'язаних у ньому елементарних збуджень $W=W(N)$.

При $\sigma=+1$ з позитивності інтеграла руху $N$ в (22) та співвідношень (23) та (24) випливає, що при будьяких значеннях $\lambda$ можливі будь-які додатні значення $\varepsilon$. При цьому гранична умова (15) не накладає ніяких додаткових обмежень на область існування розв'язку, яка визначається, таким чином, простим співвідношенням

$\varepsilon \geq 0$

При $\sigma=-1$ (коли розв'язок існує тільки при $\lambda>0$ ) з позитивності величини $N$ в (28) та співвідношення

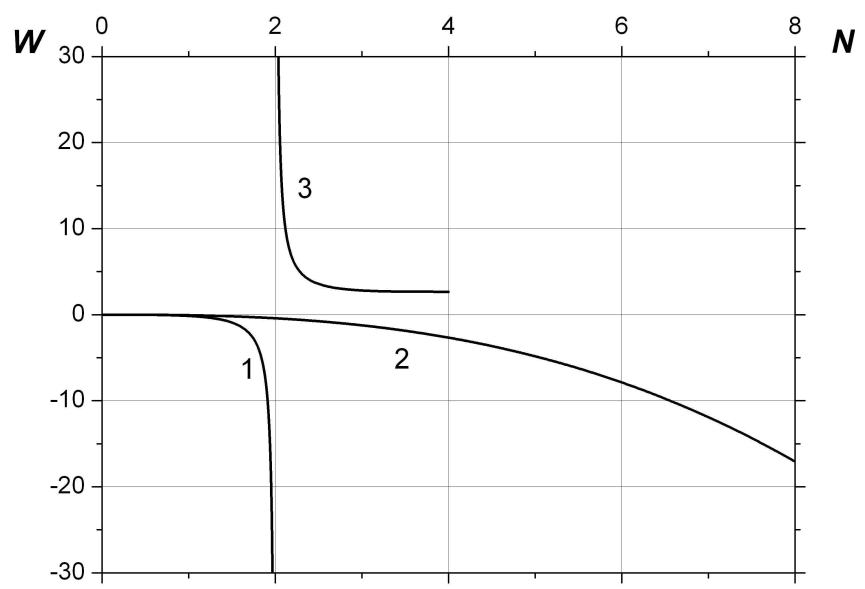

Рис. 3. Залежності $W=W(N)$ для трьох можливих типів нелінійних локалізованих станів: $a) \sigma=+1, \lambda=+1$ (крива 1$) ; b)$ $\sigma=+1, \lambda=-1$ (крива 2); c) $\sigma=-1, \lambda=+1$ (крива 3)

(29), а також з граничної умови (15) випливає, що і в цьому випадку область існування розв'язку також визначається співвідношенням (31).

Значення $\varepsilon=0(\omega=0)$ відповідає нижній межі спектра лінійних хвиль.

На рис. 2 наведено залежності $\omega=\omega(N)$ для всіх трьох можливих локалізованих станів для значень $\lambda= \pm 1\left(N^{*}=2\right)$ (враховані області припустимих значень $N(23),(24)$ і (29)).

На рис. 3 наведено залежності $W=W(N)$ для всіх можливих локалізованих станів $\left(\lambda= \pm 1, N^{*}=2\right)$.

Якщо продиференціювати залежність (27) по $N$ та скористатися співвідношеннями (22) і $(28)$ для $N(\varepsilon)$, то легко переконатися у виконанні звичайного для одночастотних солітонів співвідношення

$\frac{\partial W}{\partial N}=\omega$

що наявне в консервативних нелінійних системах, які мають інтеграл руху $N$. Таким чином, частота нелінійного локального коливання відіграє роль хімічного потенціалу для зв'язаних у ньому елементарних збуджень.

\section{3. Висновки}

У даній роботі у рамках нелінійного рівняння Шредінгера $з$ довільним знаком нелінійності досліджено всі можливі стаціонарні стани, які локалізовані на нелінійному дефекті (поблизу плоского дефектного шару), при різних властивостях цього дефекту. Показано, що результат можна трактувати мовою еле- 
ментарних збуджень, які взаємодіють між собою та $з$ дефектом.

Встановлено, що у нелінійному середовищі з дефектним шаром, що має нелінійні властивості, локалізовані на такому дефекті стани можливі при будьякому знаку ангармонізмів (будь-якому знаку $\sigma$ ) у випадку притягання елементарних збуджень до дефектного шару $(\lambda>0)$. При взаємному притяганні між збудженнями $(\sigma=+1)$ локалізація нелінійного збудження поблизу дефектного шару можлива навіть при відштовхуванні елементарних збуджень від дефекту $(\lambda<0)$. У випадку $\sigma=-1$ (відштовхування між збудженнями) нелінійні локалізовані збудження можливі тільки при $\lambda>0$. Проведено квазікласичне квантування знайдених локалізованих мод, і отримано залежність повної енергії системи від повної кількості елементарних збуджень (квазічастинок).

Отримані результати можуть бути корисні для вивчення локалізованих станів у системі з двома нелінійними дефектами i, на основі останньої, в періодичній системі нелінійних дефектів (плоских дефектних шарів) у нелінійному середовищі.

1. Y. Kivshar and G. Agrawal, Optical Solitons: From Fibers to Photonic Crystals (Academic, New York, 2003).

2. H.S. Eisenberg, Y. Silberberg, R. Morandotti, A.R. Boyd, and J.S. Aitchison, Phys. Rev. Lett. 81, 3383 (1998).

3. А.М. Косевич, А.С. Ковалев, ФНТ 1, 1544 (1975).

4. М.М. Богдан, И.В. Герасимчук, А.С. Ковалев, ФНТ 23, 197 (1997).

5. I.V. Gerasimchuk and A.S. Kovalev, J. Phys.: Condens. Matter 13, L885 (2001).

6. K. Li, P.G. Kevrekidis, B.A. Malomed, and D.J. Frantzeskakis, Phys. Rev. E 84, 056609 (2011).

7. А.М. Косевич, А.С. Ковалев, Введение в нелинейную физическую механику (Наукова думка, Киев, 1989).

8. М.М. Богдан, А.С. Ковалев, Письма в ЖЭТФ 31, 213 (1980).

Одержано 13.12.11
ЛОКАЛИЗОВАННЫЕ СОСТОЯНИЯ В НЕЛИНЕЙНОЙ

СРЕДЕ С ПЛОСКИМ ДЕФЕКТНЫМ СЛОЕМ, ОБЛАДАЮЩИМ НЕЛИНЕЙНЫМИ СВОЙСТВАМИ

И.В. Герасимчук, П.К. Горбач, П.П. Довгопольй

$\mathrm{P}$ е $з$ ю м е

В рамках квазиклассического подхода изучены солитонные состояния, локализованные вблизи плоского дефектного слоя, обладающего нелинейными свойствами, при разных знаках нелинейности среды и разном характере взаимодействия элементарных возбуждений системы с дефектным слоем. Дана квантовая интерпретация этих нелинейных локализованных мод на языке связанных состояний большого числа элементарных возбуждений. Определены области существования и исследованы свойства таких состояний в зависимости от характера взаимодействия элементарных возбуждений между собой и с дефектом.

LOCALIZED STATES IN A NONLINEAR MEDIUM CONTAINING A PLANE DEFECT LAYER WITH NONLINEAR PROPERTIES

\section{I.V. Gerasimchuk ${ }^{1}$, P.K. Gorbach ${ }^{2}$, P.P. Dovhopolyi ${ }^{2}$}

${ }^{1}$ Institute of Magnetism, Nat. Acad. of Sci. of Ukraine and Ministry of Education and Science,

Youth and Sport of Ukraine

(36b, Academician Vernadsky Blvd., Kyiv 03142, Ukraine;

e-mail: igor.gera@gmail.com)

${ }^{2}$ National Aviation University

(1, Cosmonaut Komarov Ave., Kyiv 03058, Ukraine)

$\mathrm{S}$ u m m a r y

In the framework of quasiclassical approach, soliton states localized near a plane defect layer with nonlinear properties have been studied at different signs of nonlinearity and different characters of interaction between elementary excitations in the system and the defect layer. The quantum-mechanical interpretation of corresponding nonlinear localized modes is proposed in terms of bound states of a large number of elementary excitation. The existence domains of such states are determined. The properties of those states and their dependence on the character of interaction of elementary excitations with one another and with the defect are studied. 